JMB

\title{
Solution Structure of Human GAIP (G $\alpha$ Interacting Protein): A Regulator of G Protein Signaling
}

\section{Eva de Alba', Luc De Vries², Marilyn Gist Farquhar² and Nico Tjandra*}

${ }^{1}$ Laboratory of Biophysical Chemistry, Building 3 National Heart, Lung, and Blood Institute, National Institutes of Health, Bethesda MD 20892-0380, USA

${ }^{2}$ Division of Cellular and Molecular Medicine and the Department of Pathology University of California at San Diego, La Jolla, CA 920930651, USA

\begin{abstract}
The solution structure of the human protein GAIP ( $\mathrm{G} \alpha$ interacting protein), a regulator of $G$ protein signaling, has been determined by NMR techniques. Dipolar couplings of the oriented protein in two different liquid crystal media have been used in the structure calculation. The solution structure of GAIP is compared to the crystal structure of an homologous protein from rat (RGS4) complexed to the $\alpha$-subunit of a $\mathrm{G}$ protein. Some of RGS4 residues involved in the G $\alpha$-RGS binding interface have similar orientations in GAIP (free form), indicating that upon binding these residues do not suffer conformational rearrangements, and therefore, their role does not seem to be restricted to $G \alpha$ interaction but also to RGS folding and stability. We suggest that other structural differences between the two proteins may be related to the process of binding as well as to a distinct efficiency in their respective GTPase activating function.
\end{abstract}

(C) 1999 Academic Press

Keywords: GAIP; G protein; NMR; dipolar couplings; signaling pathway

\section{Introduction}

Many of the processes necessary for cell life depend on signaling pathways through which the environments inside and outside the cell are connected. The information from the cell exterior is processed by means of a cascade of molecular interactions until the desired response is achieved. This is the so-called signaling pathway. There are proteins responsible for switching it on and off, that is, making the cell able or not to respond to external signals. One of the most important protein families having this function are $G$ proteins (Freissmuth et al., 1989; Kaziro et al., 1991; Hepler \& Gilman, 1992). These are GTP (guanosine triphosphate) binding proteins and are heterotrimers consisting of subunits $\alpha, \beta$ and $\gamma$. When $G$ proteins are inactive (the signaling pathway is switched off), the $\alpha$-subunit is bound to the $\beta$ and $\gamma$-subunits and to GDP (guanosine diphosphate). In contrast, when the $G$ protein is active and the signaling pathway

Abbreviations used: GAIP, G $\alpha$ interacting protein; RGS, regulator of G protein signaling; GAP, GTPaseactivating protein; NOE, nuclear Overhauser effect; NOESY, NOE spectroscopy; ROESY, rotating frame Overhauser effect spectroscopy.

E-mail address of the corresponding author: nico@helix.nih.gov is on, the $\alpha$-subunit is dissociated from the $\beta-\gamma$ complex and is bound to GTP. The inactivation of the pathway is accomplished through GTP hydrolysis to GDP, therefore, the rate of GTP hydrolysis determines the time the $G$ protein is active and consequently the duration of the physiological response.

Although G proteins are GTPases, there are other proteins that help them to perform this function. This type of proteins are called GTPase-activating proteins or GAPs. Recently, a novel family of regulators of $G$ protein signaling (RGS) has been identified (De Vries et al., 1995; Druey et al., 1996; Koelle \& Horvitz, 1996; De Vries \& Farquhar, 1999). All of its biochemically studied members have been shown to act as GAPs (Berman \& Gilman, 1998). RGS proteins share a $\sim 130$ residue core, called the RGS box, that accounts for the GAP activity (Faurobert \& Hurley, 1997; Popov et al., 1997). Nevertheless, the emerging biochemical information concerning the RGS protein family suggests that a more complex scenario is taking place. For example, it has been shown that the GAP function can be dependent on the type of receptor that interacts with the $\mathrm{G}$ protein (Xu et al., 1999). There exists evidence that full-length RGS proteins are much more efficient as GAPs than the RGS box alone when tested in vivo (Chen \& Lin, 1998) and it has been suggested that the regulation 
by RGS proteins could be related not only to their GAP activity but also to a competition for effector binding (Hepler et al., 1997).

Another important characteristic of RGS proteins is that most of them seem to interact preferentially with the $\mathrm{G} \alpha_{i}$ class (De Vries et al., 1995, 1998a; Berman et al., 1996a), which includes $\mathrm{G} \alpha_{\mathrm{i} 1}, \mathrm{G} \alpha_{\mathrm{i} 2}$, $\mathrm{G} \alpha_{\mathrm{i} 3}, \mathrm{G} \alpha_{\mathrm{o}}, \mathrm{G} \alpha_{\mathrm{t}}$ and $\mathrm{G} \alpha_{\mathrm{z}}$. The $\mathrm{G} \alpha_{\mathrm{i}}$ subfamily is involved in functions such as the inhibition of adenylyl cyclases, the activation of $\mathrm{K}^{+}$and $\mathrm{Ca}^{2+}$ channels and the activation of cyclic guanosine monophosphate phosphodiesterases (Neer, 1995). Interaction and GAP activity toward members of the $\mathrm{G} \alpha_{\mathrm{q}}$ and $\mathrm{G} \alpha_{12}$ (regulators of $\mathrm{K}^{+}$and $\mathrm{Na}^{+}$ channels) subfamilies have been evidenced (Kozasa et al., 1998; Hart et al., 1998), but apparently RGS do not show affinity for the $\mathrm{G} \alpha_{\mathrm{s}}$ (stimulators of adenylyl cyclases) class. From the different RGS proteins the most widely studied in biochemical terms are RGS4 (Druey et al., 1996) and GAIP (De Vries et al., 1995, 1996). Concerning the RGS box, there is not a clear distinction between the specificity of the two, although it has been shown that GAIP is a slightly more efficient GAP for $\mathrm{G} \alpha_{\mathrm{z}}$ than RGS4 (Popov et al., 1997; Wang et al., 1998), while the opposite occurs for $\mathrm{G} \alpha_{\mathrm{q}}$ (Hepler et al., 1997). In addition, it has been suggested that GAIP, RGSZ1 and RET-RGS1 form a subfamily of Gz GAPs within the RGS proteins (Wang et al., 1998). With respect to parts of the sequence outside the RGS box, GAIP and RGS4 have different functions and possibly different localizations (De Vries et al., 1998a,b).

The interaction between RGS and G $\alpha$ is favored when the latter is either bound to GTP or bound to GDP and $\mathrm{AlF}_{4}^{-}$(Berman et al., 1996b). This last form has been shown to be an analog of the transition state of GTP hydrolysis (Coleman et al., 1994).

We have determined the solution structure of the human regulator GAIP by NMR in order to give insight into the structure-function relationships of this protein family.

\section{Results}

\section{GAIP structure determination}

Although GAIP is a 217 residue protein, we have studied only the 128 residue core known to be responsible for its $\mathrm{G} \alpha$ interaction (De Vries et al., 1995) and GAP activity (Popov et al., 1997; Fischer et al., 1999). GAIP backbone and side-chain resonance assignments have been obtained using ${ }^{15} \mathrm{~N}$ and ${ }^{15} \mathrm{~N},{ }^{13} \mathrm{C}$-labeled samples for heteronuclear magnetic resonance experiments (Materials and Methods). Only five amide resonances have not been observed in the NMR spectra, probably due to their exchange properties at the rather high $\mathrm{pH}$ value for NMR studies that has been used (pH 7.2). The assignment of the side-chains is complete in more than $95 \%$. The ${ }^{13} \mathrm{C}^{\alpha}$ secondary shifts as well as the sequential and short NOEs represented in
Figure 1 indicate that the structure is mainly $\alpha$-helical with loops connecting the helices. The chemical shift values of ${ }^{13} \mathrm{C}^{\alpha},{ }^{13} \mathrm{C}^{\beta},{ }^{13} \mathrm{C}^{\prime},{ }^{1} \mathrm{H}^{\alpha}$ and ${ }^{15} \mathrm{~N}$ were used to obtain information about $\phi$ and $\psi$ angles using the program TALOS (Cornilescu et al., 1999). TALOS assigns a range of $\phi$ and $\psi$ angles to the protein of unknown structure on the basis of the similarity between the measured secondary shifts and those from a database, as well as between the amino acid type. Only the statistically significant angles reported by TALOS (mainly for the $\alpha$-helical regions) were considered as structural restraints.

Triple resonance NOESY experiments have been used to obtain nuclear Overhauser effects (NOE) derived distances. NOE intensities were translated to a continuous distribution of interproton distance restraints. The NOE intensities were calibrated through a relationship between NOEs characteristic for $\alpha$-helices and average distances observed in three-dimensional protein structures. For the great majority of the distances an error of $\pm 25 \%$ of the distance was applied to obtain lower and upper limits. The error was increased to $35 \%$ for some distances, usually involving protons whose NOEs could be contaminated by spin-diffusion processes. All intraresidue NOEs were assigned an error of $\pm 35 \%$ of the distance. The intraresidue NOEs used as distance restraints do not involve protons separated by less than three bonds. Stereospecific assignments of $\mathrm{H}^{\beta}$ were obtained using the combined information from HNHB (Archer et al., 1991) and a three-dimensional ${ }^{15} \mathrm{~N}$ separated ROESY with a mixing time of $40 \mathrm{~ms}$.

Dipolar couplings of $\mathrm{NH}, \mathrm{C}^{\alpha} \mathrm{H}^{\alpha}, \mathrm{C}^{\alpha} \mathrm{C}^{\prime}$ and $\mathrm{NC}^{\prime}$ vectors $\left({ }^{1} \mathrm{D}_{\mathrm{NH}},{ }^{1} \mathrm{D}_{\mathrm{C} \alpha \mathrm{H}},{ }^{1} \mathrm{D}_{\mathrm{C} \alpha \mathrm{C}^{\prime}},{ }^{1} \mathrm{D}_{\mathrm{NC}^{\prime}}\right.$, respectively) have been used in structure calculation. In order to obtain these parameters it is necessary that the protein shows a preferred orientation in the space so that the dipolar couplings do not average to zero. Liquid crystals generated by bicelles (Tjandra et al., 1997; Tjandra \& Bax, 1997; Bax \& Tjandra, 1997) and bacteriophages (Clore et al., 1998a; Hansen et al., 1998) were used to obtain certain degree of alignment. For the protein sample containing bicelles only ${ }^{1} \mathrm{D}_{\mathrm{NH}}$ dipolar couplings were measured. The dipolar couplings of all the abovementioned bond vectors were measured in the sample containing bacteriophages. The value of the residual dipolar couplings depends on the orientation of the bond vector with respect to the alignment tensor, which in turn has a determined orientation with respect to the molecular frame. For this reason, dipolar couplings provide structural information complementary to the classical distance restraints obtained from NOEs. Furthermore, since dipolar couplings are structural parameters obtained independently from NOEs, they can also be used to confirm the consistency of the structural information derived from the latter. Additionally, in the case of multidomain proteins, where there are few NOEs connecting the different subdomains, dipolar couplings have been proven to be the unique way to define their relative orientation 


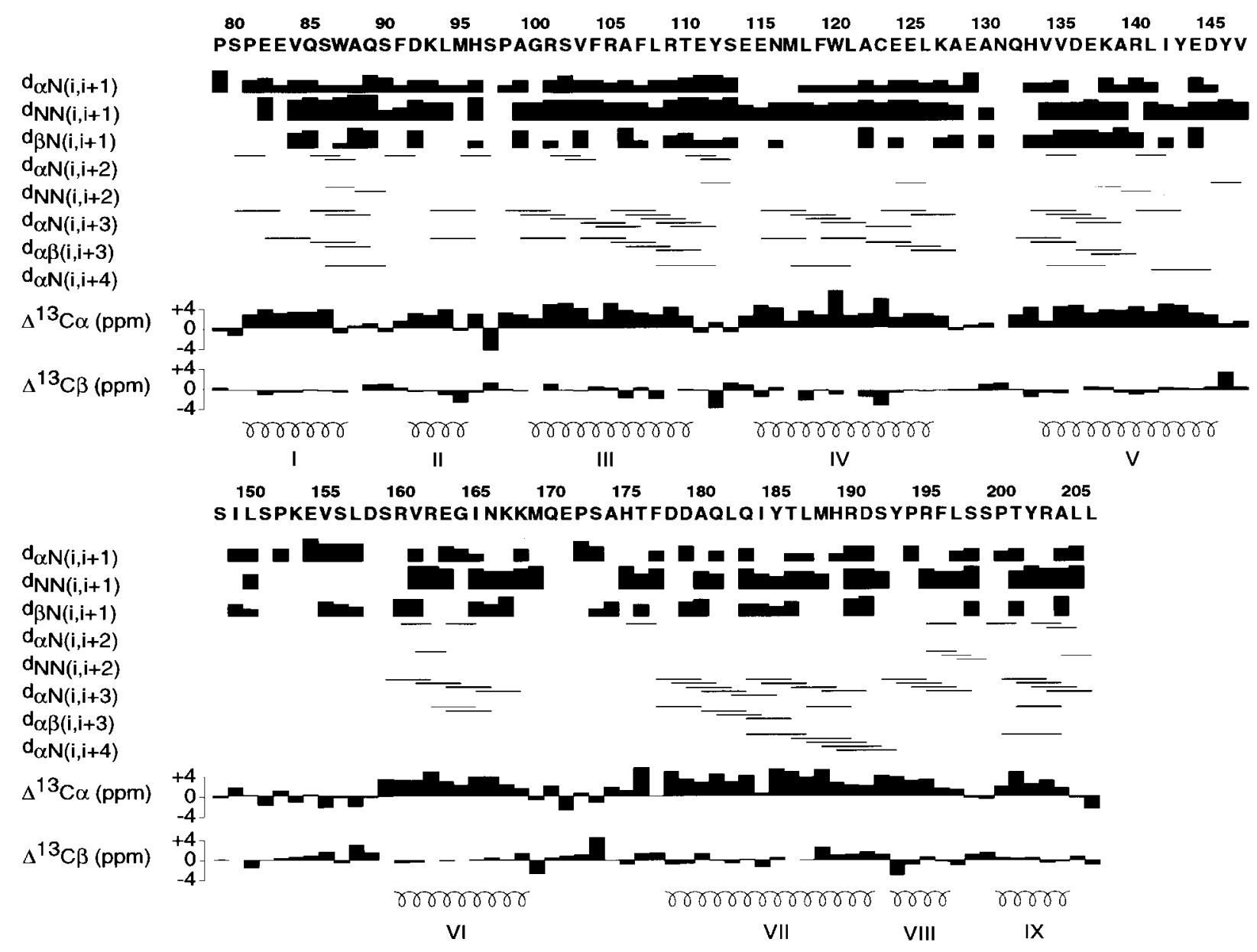

Figure $1 .{ }^{13} \mathrm{C}^{\alpha}$ and ${ }^{13} \mathrm{C}^{\beta}$ secondary shifts, as well as short and medium-range NOEs characteristic of $\alpha$-helices versus GAIP amino acid sequence. The location of the different helices in the sequence is indicated. Secondary shifts have been obtained using the random coil values reported by Spera \& Bax (1991).

by NMR (Drohat et al., 1999). In order to determine the orientation of the bond vector responsible for the residual dipolar coupling it is necessary to know the axial and the rhombic components of the alignment tensor. This information was obtained from the histogram of the dipolar couplings distribution as proposed by Clore et al. (1998b). Initial values of the axial component $\left(\mathrm{Da}^{\mathrm{NH}}\right)$ and the rhombicity (R) obtained from the histogram, were optimized by minimizing the differences between the observed and the calculated dipolar couplings (Tjandra et al., 1997; Clore et al., 1998c) using preliminary structures. The calculated $\mathrm{Da}^{\mathrm{NH}}$ is $-9 \mathrm{~Hz}$ and $-11.5 \mathrm{~Hz}$ for the bicelle and the bacteriophage samples, respectively. $R$ values are 0.28 for the bicelle sample and 0.44 for the bacteriophage sample. The differences in the axial component as well as in the rhombicity indicate that the alignment tensor is different in each liquid crystal medium. Therefore, two alignment tensors with different orientations were included in the structure calculation. Figure 2(a) and (b) show the ${ }^{1} \mathrm{D}_{\mathrm{NH}}$ values measured in the bicelle and bacteriophage media, respectively. The differences between the two sets of dipolar couplings are due to the angles that the $\mathrm{NH}$ bond vectors form with the alignment tensors, as well as the different rhombicities and magnitudes of these tensors. As can be observed in Figures 2(a) and (b), residues in helices VII and VIII (vide infra), have the largest negative values of the dipolar couplings, indicating that those helices are nearly parallel to the $z$ axis of the alignment tensors. In addition, for these two helices both sets of dipolar couplings are very similar. Since rhombicity effects are minimum for vectors that lie close to the $z$ axis of the alignment tensor, the similarity of the dipolar couplings of helices VII and VIII in the two media indicates that first, the $z$ axis of both alignment tensors have close orientations, and second, the magnitude of the alignment cannot be very different. Residues belonging to helices II and III (vide infra) have some of the most positive dipolar couplings. This is expected for $\mathrm{NH}$ bond vectors forming a $90^{\circ}$ angle with respect to the $z$ axis of the alignment tensor. The dipolar couplings of residues belonging to these helices are strikingly different in the two-liquid crystal media. This behavior is due to the different rhombicity, which has the largest effect on the dipolar couplings of $\mathrm{NH}$ bond vectors perpendicular to the $z$ axis of the 

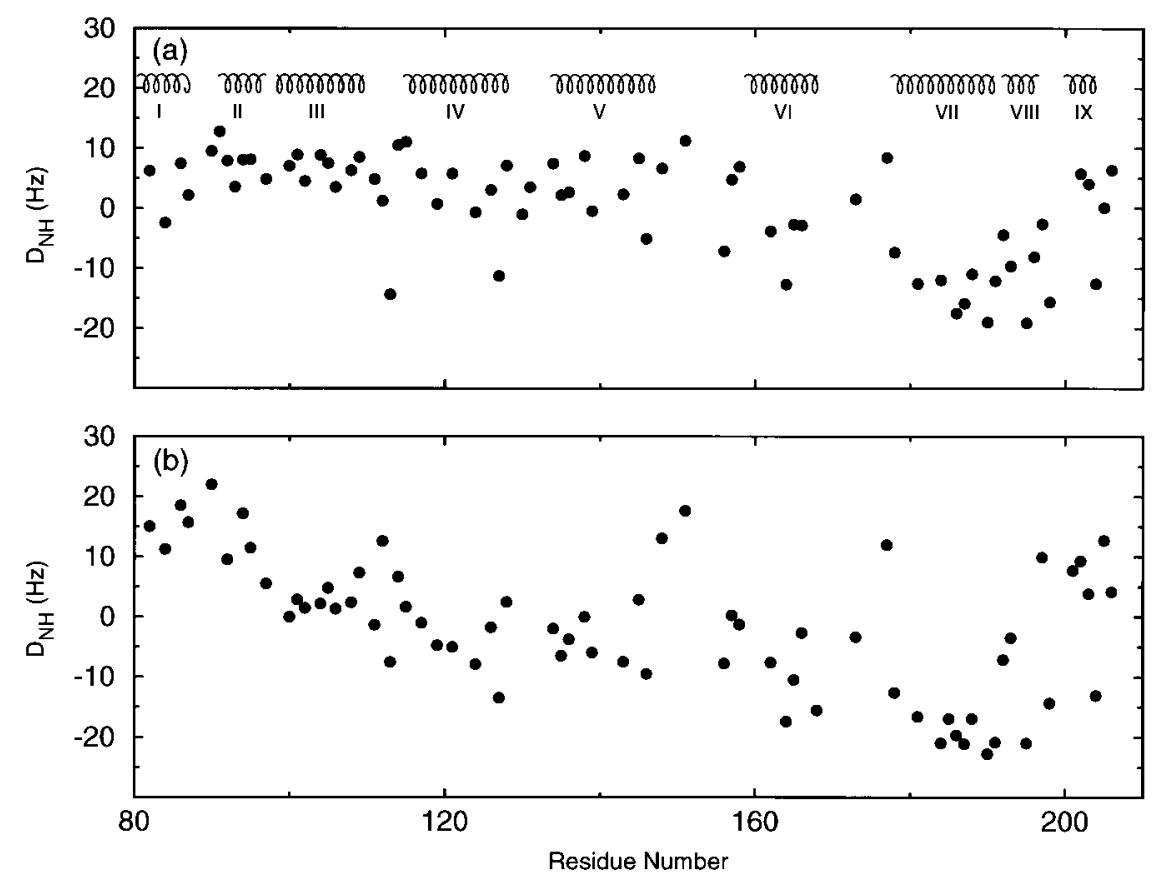

Figure 2. $\mathrm{NH}$ amide residual dipolar couplings versus GAIP amino acid sequence in (a) bicelle liquid crystal and (b) bacteriophage liquid crystal. Location of secondary structure elements is indicated.

alignment tensor, as well as to the orientation of the $x$ and $y$ axis. It is noteworthy that helices II and III have similar dipolar couplings in the bicelle medium, although different in the phage medium. The former result can be explained if helices II and III form similar angles (close to $90^{\circ}$ ) with respect to the $z$ axis of the alignment tensors. Since the rhombicity in the bicelle medium is small, the relative orientation of the helices with respect to the $x$ and $y$ axis cannot be deduced easily. While the second observation indicates that, due to the substantially larger rhombicity in the phage medium, the orientations of the two helices can now be differentiated through their dependence on the $x$ and $y$ axis. These results illustrate the utility and complementarity of the structural information given by residual dipolar couplings resulting from different alignment tensors.

As additional restraints for structure calculation hydrogen bonds were included for the helical regions determined by the $\mathrm{C}^{\alpha}$ secondary shifts and the NOE characteristic of $\alpha$-helices (Figure 1) (Wüthrich, 1986).

\section{GAIP three-dimensional structure and structure quality}

Figure 3 represents a ribbon diagram of the minimized average structure calculated for GAIP. This protein is formed by nine $\alpha$-helices connected by loops. The location of the helices in GAIP sequence, on the basis of the secondary ${ }^{13} \mathrm{C}^{\alpha}$ shifts, as well as short and medium-range NOEs (Figure 1), is as follows. Helix I (residues 81-87), helix II (residues 91-96), helix III (residues 98-111), helix IV (residues 115-127), helix V (residues 134145), helix VI (residues 160-168), helix VII (residues
178-191), helix VIII (residues 192-196) and helix IX (residues 200-204).

The largest loops are the ones connecting helices $\mathrm{V}$ and VI (loopV-VI) and helices VI and VII (loopVI-VII), with 14 and 9 residues, respectively. The right-hand-side of the structure (Figure 3 ) is a fourhelix bundle formed by helices IV, V, VI and VII. The left-hand-side of the structure is composed by helices I, II, III, VIII and IX. Residue contacts between helices II, III, IV, VII and VIII define the relative orientation between the two parts. So far, there is no evidence for the two parts to be structurally nor dynamically independent.

Only proteins containing four-helix bundles appear as structurally similar to GAIP when searching the database with the program Dali

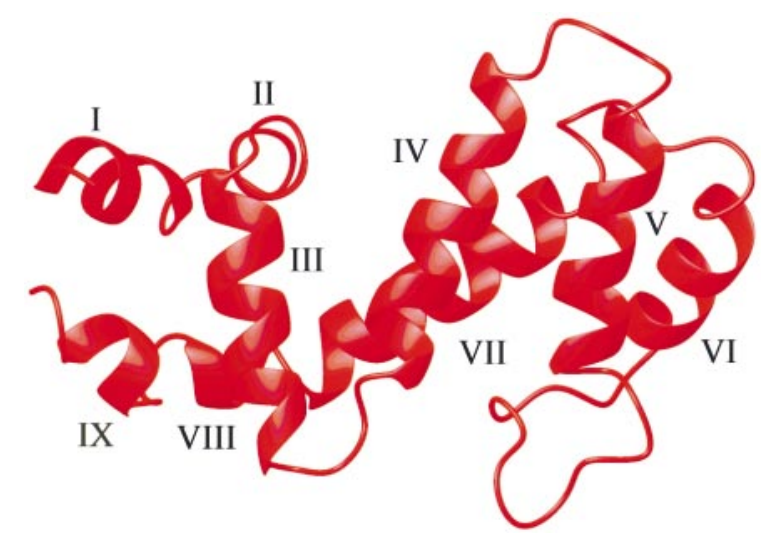

Figure 3. Ribbon diagram of the backbone of the minimized average structure. Helices are Romannumbered. Figures 3-8 have been generated using the program MOLMOL (Koradi et al., 1996). 
(Holm \& Sander, 1993). Some of those proteins are for example, myohemerythrin and cytochrome b562. The first protein is an oxygen binding protein, the second is involved in electron transport. A comparison between the four-helix bundles of these proteins and GAIP reveals that GAIP's four-helix bundle is shorter, specially with respect to helices V and VI. It is also apparent that the characteristic twist of two of the helices with respect to the other two is more pronounced in GAIP than in the other proteins mentioned. Another important difference concerns the packing between helices V and VI in GAIP's four-helix bundle, which "opens" toward the end and the beginning of helices V and VI, respectively. In contrast, these two helices in myohemerythrin and cytochrome $b 562$ are twisted only slightly.

Figure 4 shows a superposition of the heavy backbone atoms of the 20 calculated structures with the lowest energy. These structures do not show NOE violations greater than $0.45 \AA$, nor dihedral violations greater than $4^{\circ}$. Some of the most relevant structural information is indicated in Table 1. An r.m.s.d. (root-mean-square deviation) of $0.46 \AA$ when superimposing the backbone heavy atoms of the protein excluding loopV-VI and loopVI-VII indicates that the precision among the calculated structures is quite good.

The quality of the structure is tested using the $Q$ factor calculated with dipolar couplings, (Ottiger \& Bax, 1999; Drohat et al., 1999). The $Q$ factor for ${ }^{1} \mathrm{D}_{\mathrm{NH}}$ has been calculated using three sets of structures. The first set was calculated without any dipolar coupling information, the second and the third sets with all but the ${ }^{1} \mathrm{D}_{\mathrm{NH}}$ in bacteriophage and bicelle medium, respectively. The calculated $Q$ factors for the mentioned sets of structures are as follows:

Structures calculated without dipolar couplings:

$$
\begin{aligned}
& Q_{\mathrm{NH}}(\text { phage })=0.48 \pm 0.04 \\
& Q_{\mathrm{NH}}(\text { bicelle })=0.51 \pm 0.03
\end{aligned}
$$

Structures calculated with all but the target dipolar coupling:

$$
\begin{aligned}
& Q_{\mathrm{NH}}(\text { phage })=0.26 \pm 0.05 \\
& Q_{\mathrm{NH}}(\text { bicelle })=0.24 \pm 0.02
\end{aligned}
$$

The $Q$ factor for ${ }^{1} \mathrm{D}_{\mathrm{C} \alpha \mathrm{H}}$ cannot be reliably used as a measure of the overall structure quality due to the low number of observed ${ }^{1} D_{\mathrm{C} \alpha \mathrm{H}}$ which does not sample the structure properly.

In general, the $Q$ factors of NMR structures not refined with dipolar couplings range from 0.6 to 0.9. The lower $Q$ factors for the structures refined with all but the target dipolar coupling are indica-

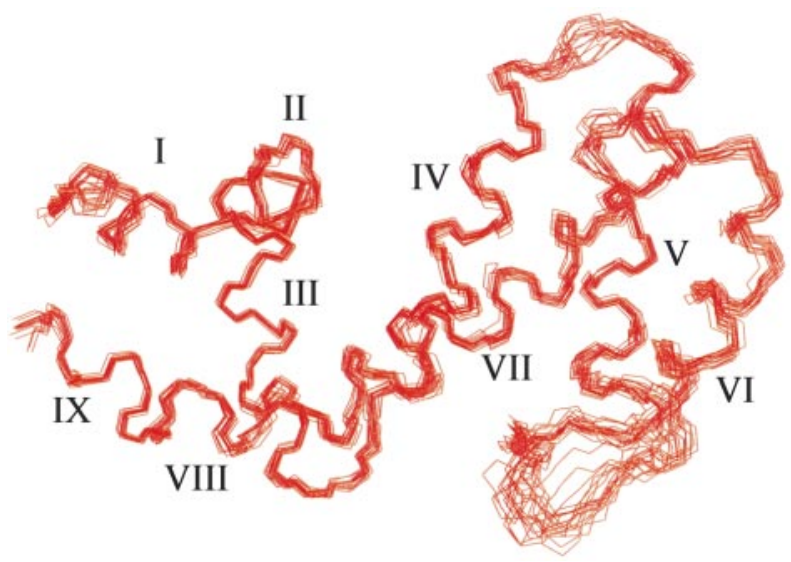

Figure 4. Superposition of the 20 structures with the lowest energy, excluding the loops connecting helices $\mathrm{V}$ to VI and VI to VII. Helices are indicated with Roman numbers.

tive of an improvement in the quality of the structure by the use of dipolar couplings.

\section{Comparison between GAIP and RGS4 structures}

The structure of the complex between rat RGS4 and $\mathrm{G} \alpha_{\mathrm{i} 1}-\mathrm{GDP}-\mathrm{AlF}_{4}$ has been determined by X-ray crystallography (Tesmer et al., 1997). The RGS domains of the human protein GAIP and RGS4 share approximately $60 \%$ of sequence similarity. Therefore, the comparison between both structures can reveal some clues about the way RGS proteins interact with $G \alpha$ and possible differences in their efficiency as $\mathrm{G} \alpha$ regulators. Figure 5 shows the superposition of the crystal structure of RGS4 (complexed with $\mathrm{G} \alpha_{\mathrm{i} 1}$ ) and the minimized average structure calculated for GAIP. Although the complex was formed with full-length RGS4, only the RGS box shows electron density (Tesmer et al., 1997). The overall fold of both structures is very similar. The r.m.s.d. value between the crystal structure and the average solution structure when superimposing all residues but loopV-VI and loopVI-VII is $1.32 \AA$. The largest structural differences are located in helices II and VI, as well as in the loop connecting helices V and VI.

The binding loci of RGS4 to G $\alpha$ are located in loopIII-IV, loopV-VI, and at the end and the beginning of helices VII and VIII, respectively, as well as the beginning of helix VI (Figure 5) (Tesmer et al., 1997). Therefore, the structural differences between GAIP and RGS4 in these regions provide insight into their interaction with $G \alpha$. The structures of loopIII-IV, loopIV-V and VI-VII are very similar for both structures. This is also true for helices III, IV, VII and VIII. In contrast, loopV-VI and helix VI are substantially different (Figure 5).

The majority of the interactions responsible for G $\alpha$-RGS4 binding are of the electrostatic type (Tesmer et al., 1997). Only two hydrophobic RGS4 
Table 1. Structural statistics

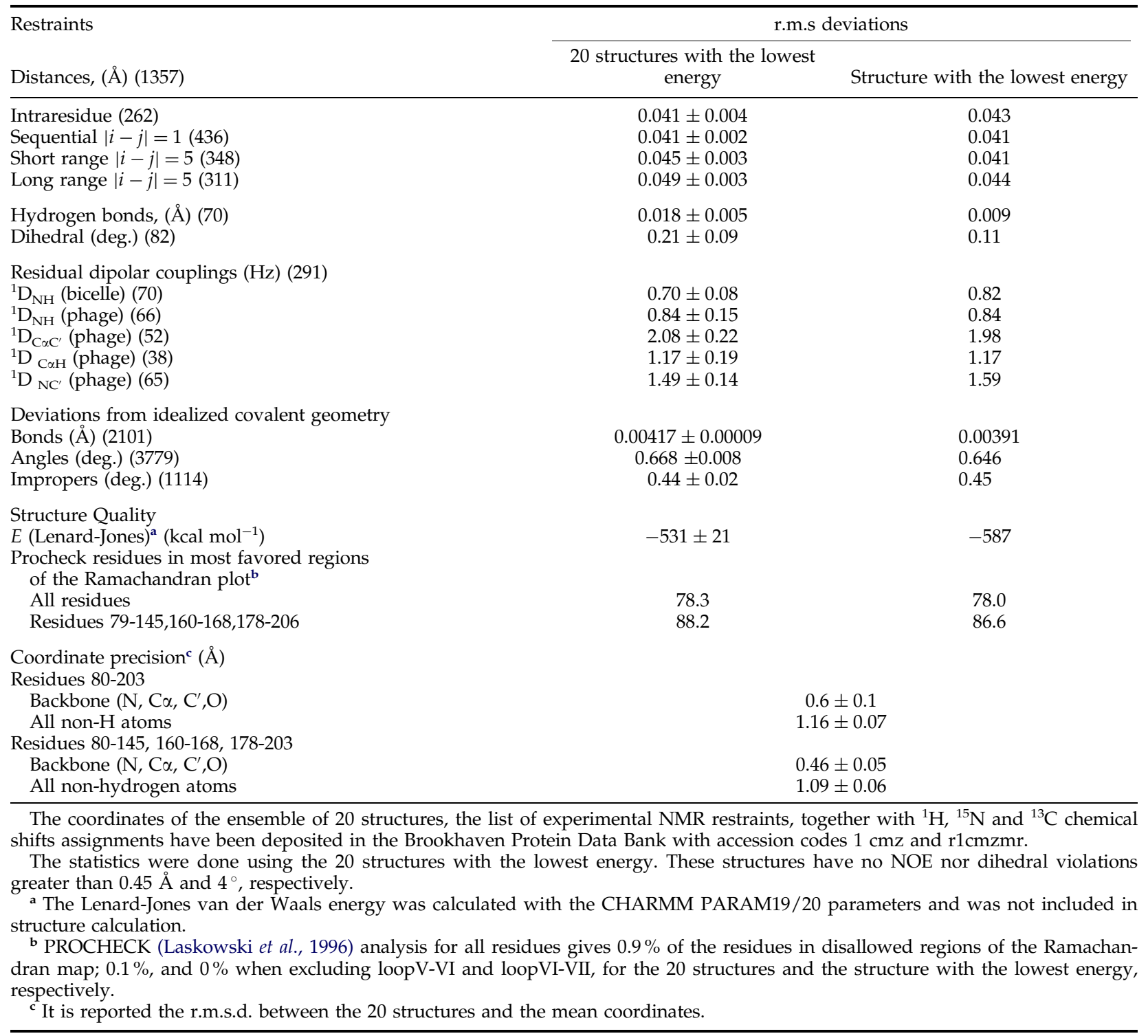

residues are involved in the binding surface. These residues are Y84 and L159, which are conserved in GAIP (Y112, L187) and located in loopIII-IV and helix VII, respectively. Other important residues for binding which are close to the hydrophobic residues are RGS4-N88 (GAIP-N116) and RGS4N128 (GAIP-S156). Figure 6 shows the conformation of these residues for RGS4 and GAIP when superimposing the backbone heavy atoms of the secondary structure elements of both proteins. The side-chains of residues GAIP-L187 and GAIP-S156 are determined with acceptable resolution considering the 20 structures of the NMR ensemble, with r.m.s.d. value of $0.82 \AA$ and $0.81 \AA$ for the nonhydrogen atoms of their respective side-chains. Only the minimized average structure is shown in Figure 6 for clarity. Residue GAIP-L187 shows a preferred orientation very similar to that present in complexed RGS4. This may indicate that upon binding this residue does not undergo large confor- mational changes, since GAIP is in its free state while RGS4 is complexed. It is noteworthy that residue RGS4-Y84 and the equivalent in GAIP (Y112), has positive $\phi$ angles, not only in the crystal structure but also in the 20 lowest-energy NMR structures. TALOS constraints were not included for this residue in the structure calculation, although the program also reports positive $\phi$ angle for Y112. Positive values of the $\phi$ angle are rather unusual for residues different from glycine or asparagine. The side-chain of GAIP-Y112 is disordered and cannot be compared to that in RGS4. Residues GAIP-L187 and GAIP-N116 give numerous NOE contacts between them and with residues GAIP-V155 (loopV-VI), GAIP-I184 (helix VII) and GAIP-F119 (helix IV), possibly indicating that they participate in the formation of a hydrophobic core located in the four-helix bundle (Figure 7) and therefore the importance of these residues would 


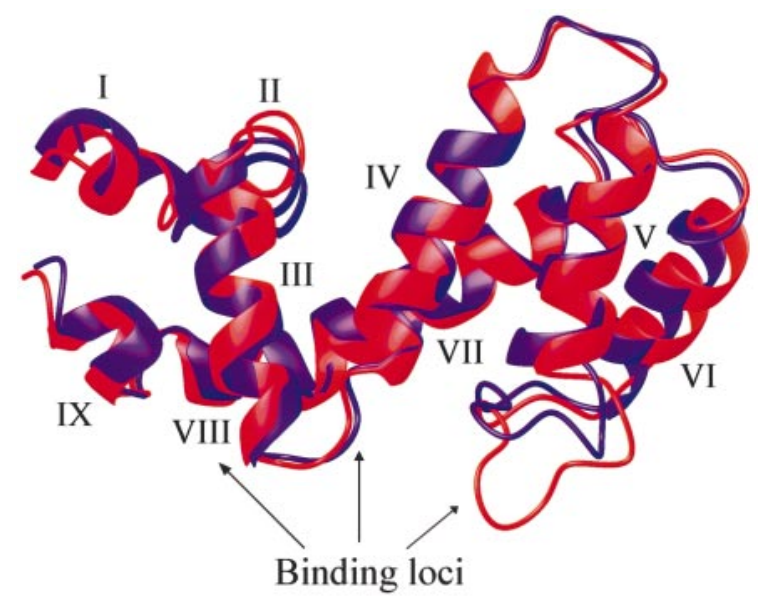

Figure 5. Ribbon diagram superimposing the average solution structure calculated for GAIP and the RGS4 moiety of the crystal structure of the RGS4-G $\alpha_{i}$ complex. The loops connecting helices V to VI and VI to VII have not been included for the superposition. GAIP and RGS4 are represented in red and blue ribbon, respectively. Helices are indicated with Roman numbers. The binding loci of RGS4 to $\mathrm{G} \alpha$ are indicated with arrows.

not be restricted to function but also probably to the folding and stability of GAIP.

The comparison between residue RGS4-N128 and GAIP-S156 is particularly important since on the basis of the crystal structure, RGS4-N128 is the only residue that is close to one of the active residues of $\mathrm{G} \alpha_{\mathrm{i} 1}$ for GTP hydrolysis (Tesmer et al., 1997). This position is occupied by either Asn or Ser in the different RGS family members, with a predominance of Asn versus Ser (Wang et al., 1998). Although both side-chains are able to form hydrogen bonds, the Ser side-chain is shorter than the Asn side-chain and this may have some implications in either specificity or affinity toward different members of the $\mathrm{G} \alpha_{i}$ class. GAIP-S156 has NOE contacts with GAIP-I184 and GAIP-L187, two of the residues involved in the hydrophobic core mentioned above (Figure 7). The side-chain of RGS4-N128 in the crystal structure is also close to RGS4-I156 and RGS4-L159, which are the equivalent residues to GAIP in RGS4. This indicates that the side-chains of both (RGS4-N128 and GAIPS156) have similar orientations (Figure 6). The r.m.s.d. value for the GAIP-S156 side-chain $(0.81 \AA)$ may indicate that this residue also has a slightly restricted conformation in GAIP. This is an interesting result considering the potential importance of this residue in the GAP activity and taking into account that one of the structures is complexed and the other is free.

In RGS4 complexed with $G \alpha_{i 1}$, RGS4-R167 (GAIP-R195) forms salt bridges with RGS4-E83 (GAIP-E111) and RGS4-D163 (GAIP-D191) (Tesmer et al., 1997). According to the crystallographic studies, these interactions constitute approximately
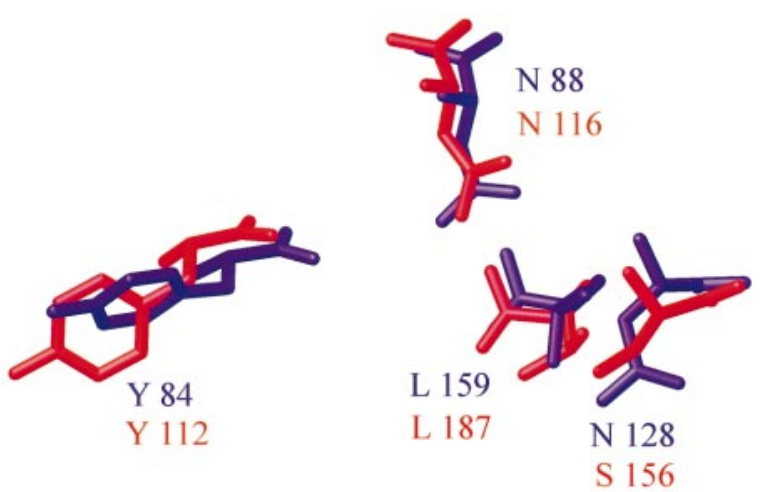

Figure 6. Comparison between RGS4 and GAIP conformation of residues known to be important for the $G \alpha$ interaction. GAIP and RGS4 residues are colored red and blue, respectively. Residue type and number are indicated.

$22 \%$ of the binding surface (Tesmer et al., 1997). In contrast, the side-chains of these residues in GAIP are flexible. These electrostatic interactions, if present in GAIP, should place the $\mathrm{H}^{\zeta}$ and $\mathrm{H}^{\varepsilon}$ protons of GAIP-F107 at distances close to $2 \AA$ and $3.5 \AA$ of $\mathrm{H}^{\beta}$ and $\mathrm{H}^{\gamma}$ protons of GAIP-R195, respectively. In contrast no NOEs involving those pairs of protons were detected in the NMR spectra of GAIP. Phenylalanine has a rather unusual NMR behavior in comparison to other aromatic residues such as tyrosine. The strong ${ }^{13} \mathrm{C}^{-1} \mathrm{H}$ dipolar interactions present in its side-chain broaden ${ }^{1} \mathrm{H}$ NMR signals, and its relatively large ${ }^{13} \mathrm{C}-{ }^{13} \mathrm{C}^{11} \mathrm{~J}$ coupling together with the low ${ }^{13} \mathrm{C}$ chemical shift dispersion, introduce non-first-order character into the spectra that makes phenylalanine residues difficult to assign. Besides, it is a common observation that for sufficiently large proteins NOE interactions involving uniformly ${ }^{13} \mathrm{C}$-enriched phenylalanine residues may be difficult to observe in four-dimensional NMR spectra (Vuister et al., 1994). Therefore, the absence of the mentioned NOEs does not mean that these residues are not conformationally restricted as observed in the crystal structure. It might be that these short interproton distances do exist but are not possible to observe with NMR.

As mentioned before, one of the largest structural differences between RGS4 and GAIP is located in loopV-VI. The sequences of this loop for both proteins are as follows:

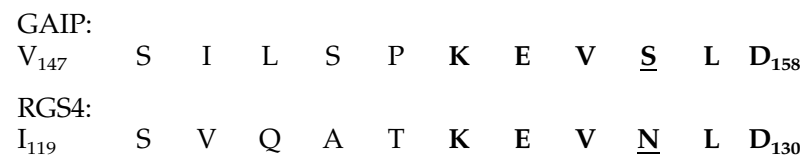

The C-terminal half of the loop (residues 153-158 in GAIP), excluding GAIP-S156 which is RGS4$\mathrm{N} 128$, is conserved in sequence between the two proteins. In contrast the sequence of the $\mathrm{N}$-terminal 


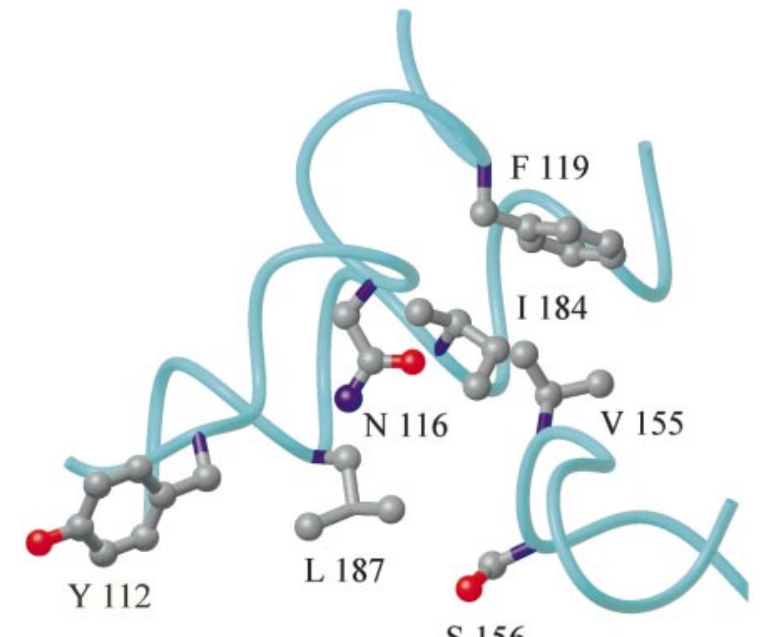

S 156

Figure 7. Side-chain conformation of some of the residues involved in the four-helix bundle hydrophobic core of the minimized average structure calculated for GAIP.

part (residues 147-152 in GAIP) is not conserved, and the largest amino acid differences include residues 150-152 in GAIP (122-124 in RGS4). The biggest structural difference within loopV-VI is located in the N-terminal part of the loop, specially in residues GAIP-P152 and GAIP-K153 (RGS4-T124 and RGS4-K125). In fact, from residue 154 to 158 in GAIP (126 to 130 in RGS4) the structure of the loop is very similar (Figure 5). Therefore, the structural differences within the loop involve the region where the largest sequence differences are located. Besides, on the basis of amide ${ }^{15} \mathrm{~N}-{ }^{1} \mathrm{H}$ heteronuclear NOE, which is an indication of the flexibility of the backbone on the picosencond to nanosecond time scale, there exists a slightly higher mobility in loopV-VI than in the center of the secondary structure elements (data not shown). The differences mentioned between RGS4 and GAIP structures can be related to binding effects present in the RGS4$\mathrm{G} \alpha_{i 1}$ complex or to the differences in the amino acid sequences of the two proteins. The lack of specific interactions between the region of the RGS4 loop, that is structurally different from GAIP and has a different amino acid sequence (residue A122 to residue T124), and the rest of RGS4 structure suggests that the first possibility is more likely.

As mentioned above, in residues GAIP-P152 and GAIP-K153 (RGS4-T124 and RGS4-K125) is where the largest differences are located. We have analyzed the interactions with other parts of RGS4 or GAIP in which these residues are involved. Residue RGS4-T124 does not form specific contacts with other parts of the protein. In contrast, RGS4-K125 forms two salt bridges, one with RGS4-D90 (helix IV) and other with RGS4-E117 (helix V). Figure 8 shows the confor-

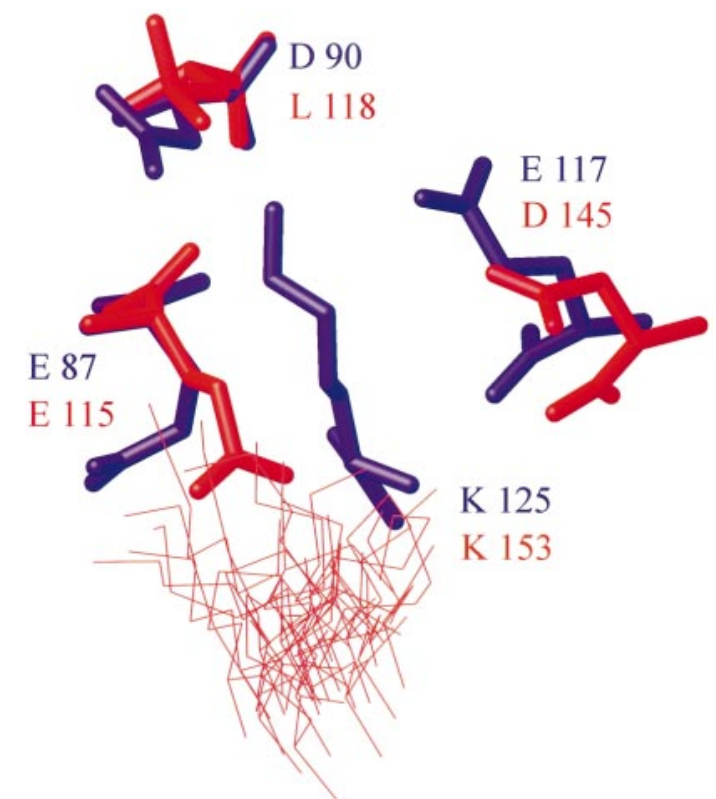

Figure 8. Comparison of RGS4 (blue) and GAIP (red) side-chain conformation of residues involved in the saltbridge interactions between loopV-VI and helices IV and V present in RGS4 but not observed in GAIP.

mation of these residues in RGS4 and the conformation of K153 in GAIP for the 20 calculated structures. This Figure also shows the side-chain of residue RGS4-E87 (helix IV). This residue has its carboxylate group pointing toward a direction opposite to that of RGS4-K125. Therefore, RGS4E87 is probably not involved in a salt bridge but its side-chain is very close to RGS4-K125. RGS4-E87 and RGS4-K125 are conserved in GAIP, and RGS4-E117 is a conserved substitution by GAIP-D145, in contrast, RGS4-D90 is not conserved (GAIP-L118). Thus, only one of the salt bridges is possible in GAIP. The salt bridges fix the side-chain of RGS4-K125 and locate some of the protons of the participating side-chains at distances between $2 \AA$ and $5 \AA$. If the conformation of GAIP-K153 were similar to that of RGS4-K125, these short distances should generate NOE. We have not seen NOEs connecting the side-chain protons of GAIP-K153 with GAIP-L118, GAIP-E115 nor GAIP-D145. These salt bridges connecting loopV-VI with helices IV and $\mathrm{V}$, may contribute to fix the position of the loop in RGS4 structure. From evidence presented in Figure 8 these interactions are not present or are at least transient in GAIP and thus, loopVVI is not fixed. Even considering the unconserved substitution of RGS4-D90 by GAIP-L118, the salt bridge to GAIP-D145 could still be formed. For this reason we suggest that this interaction could be stabilized and permanently present only in the complexed form but not in the free state of either GAIP or RGS4. RGS4- 
N128 is the only residue in loopV-VI that forms specific contacts with $G \alpha$, therefore, the fixed conformation of this loop is probably not a result of direct specific interactions between the loop and $G \alpha$, but of indirect steric restriction due to slight structural modifications that may take place upon binding.

\section{Conclusions}

The solution structure of GAIP has been determined using residual dipolar couplings resulting from the alignment of the protein in two distinct liquid crystal media. The orientation of the alignment is different in each medium, therefore, the dipolar couplings vary from the bacteriophage to the bicelle media. Both sets of data agree well with a good precision ensemble of calculated structures, once the axial component and the rhombicity of the respective alignment tensors are properly determined.

With respect to GAIP solution structure, we have shown that some of the side-chains of the residues involved in $G \alpha-R G S$ interface have a preferred orientation in GAIP similar to that present in the complexed RGS4. This is the case of GAIP-L187, whose location in a hydrophobic core suggests that, although it participates in the $\mathrm{G} \alpha$-RGS binding interface, this residue may also have an importance in the folding and stability of the RGS protein. Additionally, the NOE contacts between GAIP-S156 and some of the residues of the core, indicate that this residue may play a role in determining GAIP stability as well. This is in agreement with previous findings concerning the low expression of a mutant of human retinal RGS protein lacking the equivalent Asn residue, which has been attributed to its role in the folding and stability of the RGS protein (Natochin et al., 1998). In addition, the observed NOE contacts coincide with spatial proximity of equivalent residues in the crystal structure, this fact together with S156 low sidechain r.m.s.d., indicate that this residue populates a preferred region of the conformational space which is similar to that present in RGS4. This is the only residue that interacts with the hydrolytic site of $\mathrm{G} \alpha$ (Tesmer et al., 1997).

The protein sequences of GAIP, RGSZ1 and RET-RGS may form a subfamily in the RGS proteins. In their RGS domain the conserved N128 residue of RGS4 is replaced by Ser, and all three show high GAP activity for the $\mathrm{G} \alpha_{\mathrm{z}}$ (Wang et al., 1998). $\mathrm{G} \alpha_{\mathrm{z}}$ itself is also an outsider in that its active site diverges significantly from other $\mathrm{G} \alpha_{\mathrm{i}}$ subfamily members and shows a very low basal GTPase activity. It has been shown that the Asn to Ser substitution impairs $\mathrm{G} \alpha$ binding in human retinal RGS protein (Natochin et al., 1998). Nevertheless, since N128 in RGS4 and S156 in GAIP form contacts with some of the residues involved in the hydrophobic core of the four-helix bundle, it is possible that in each protein this core is optimized such that an amino acid substitution decreases the overall stability of the protein, consequently affecting its ability to interact. Further investigation needs to be done in order to identify the possible roles of Asn or Ser residues in different RGS family members.

On the basis of the crystallographic studies it has been proposed that the GAP activity of RGS proteins is more related to a stabilization of the transition state conformation of the $G \alpha$ loops involved in hydrolysis than to a direct participation in the catalytic site (Tesmer et al., 1997). We have shown that at least one interaction observed in complexed RGS4 is either not present or transient in GAIP. This fact suggests that it is not only the $G \alpha$ structure that may be stabilized upon binding but also the structure of the RGS protein. In this sense, it is possible that the driving force of binding are the specific interactions between the two proteins and also the stabilization of each structure independently. On the basis of the differences between RGS4 and GAIP loopV-VI structure, we suggest that upon binding some conformational rearrangements may facilitate the formation of electrostatic interactions that stabilize RGS structure.

One of the electrostatic interactions present in complexed RGS4 involves residue RGS4-D90. Since this residue is not conserved in GAIP (GAIP-L118), sequence variability in this position may have functional implications (this position is occupied by $D, E, L, S$ and $R$ in different RGS members). For example, the stabilization of GAIP upon binding with G $\alpha$ could be smaller than for RGS4, and therefore, the interaction could be more transient. This fact may have an influence in the efficiency of the GTPase activating function. Since it has been observed that RGS proteins function catalytically (Berman \& Gilman, 1998), the interaction with $G \alpha$ has to be transient such that the RGS protein can interact with many $G \alpha$ and perform its GAP activity with all of them. The structure of GAIP-G $\alpha$ complex and the study of this interaction by NMR techniques will give more insights into the molecular basis of the function and specificity of this recently discovered family of regulators of $G$ protein signaling.

The work reported herein concerns the structurefunction relationships of the RGS box of GAIP in comparison to that of RGS4, and therefore it is focused in the GTPase activating function. The similarity between the overall structures of RGS4 and GAIP indicates that the principal characteristics of the RGS fold may be conserved within the different family members. There are additional domains in full-length RGS proteins that have been implicated in interactions with other than G proteins or for which different functions have been predicted (De Vries \& Farquhar, 1999). Thus, it is important to bear in mind that the GAP activity is far from being the unique role played by this protein family. 


\section{Materials and Methods}

\section{Expression, purification and sample preparation}

The DNA sequence encoding GAIP primary structure from residue P79 to residue L206 has been inserted in a glutathione $S$-transferase (GST) fusion vector (pGEX-2T) from Pharmacia Biotech. Escherichia coli BL21(DE3) was used as an expression host. The plasmid once in E. coli was isolated and sequenced and the amino acid sequence of the expressed protein (excluding the GST sequence) is as follows:

\section{GSPGISGGGGGIP $_{79}$ SPEEVQSWAQSFDKLMHSPAG $_{100}$ RSVFRAFLRTEYSEENMLFW ${ }_{120}$ LACEELKAEANQHVV DEKAR $_{140}$ LIYEDYVSILSPKEVSLDSR $_{160}$ VREGINKKMQ EPSAHTFDDA $_{180}$ QLQIYTLMHRDSYPRFLSSP $_{200}$ TYRALL 206 PWVDSSSSLIHRD}

The induction of protein expression was performed at room temperature by the addition of isopropyl $\beta$-Dthiogalactopyranoside (Sigma) for four hours. The expression of uniformly ${ }^{13} \mathrm{C}_{,}^{15} \mathrm{~N}$-labeled protein was done by growing the bacteria in minimal medium containing $\left[{ }^{13} \mathrm{C}_{6}\right.$ ]glucose and ${ }^{15} \mathrm{NH}_{4} \mathrm{Cl}$ (Martek) as sole carbon and nitrogen sources, respectively. Cells were harvested and resuspended in $1 \times$ phosphate buffer saline at $\mathrm{pH} 7.4$ with $1 \%(\mathrm{v} / \mathrm{v})$ polyoxyethylene-sorbitan monolaurate (Sigma) and the serine protease inhibitor 4-(2-aminoethyl)-benzenesulfonyl fluoride hydrochlorine (ICN, Biomedicals), further lysed by ultrasonication and cleared by centrifugation. The supernatant was poured into a glutathione Sepharose 4B (Pharmacia Biotech) column and cleaned with $1 \times$ phosphate buffer saline at $\mathrm{pH}$ 7.4. The GST moiety was cleaved by reaction with biotinylated thrombin (Novagen) for three hours. Biotinylated thrombin was removed by the use of streptavidin agarose beads (Novagen) by shaking for 30 minutes. Beads were removed by centrifugation. The supernatant was further purified by reverse phase HPLC. Then lyophilized and washed with HPLC grade water in Centricon. The purity of the protein was further checked by mass spectrometry. The $\mathrm{pH}$ of the protein solution was adjusted to 7.2 by the addition of small amounts of $0.1 \mathrm{M} \mathrm{KOH}$. The $\mathrm{pH}$ (uncorrected for isotope effects) of protein samples in ${ }^{2} \mathrm{H}_{2} \mathrm{O}$ was 8.3 instead of 7.2 due to protein solubility in ${ }^{2} \mathrm{H}_{2} \mathrm{O}$. On the basis of the amino acid composition the extinction coefficient of GAIP at $280 \mathrm{~nm}$ is $24,870 \mathrm{M}^{-1} \mathrm{~cm}^{-1}$. This value has been used to estimate the yield of protein expression to be approximately $15 \mathrm{mg} / 4 \mathrm{l}$ culture in minimal media. The concentration of the NMR samples was between $0.6 \mathrm{mM}$ and $1 \mathrm{mM}$ and contained $10 \%{ }^{2} \mathrm{H}_{2} \mathrm{O}$, $\mathrm{NaN}_{3}$ and 5-10 $\mathrm{mM}$ dithiothreitol.

\section{NMR spectroscopy}

NMR experiments were performed on a Bruker DMX600 equipped with three-axis shielded gradient triple resonance probe at $27^{\circ} \mathrm{C}$. The spectra were processed using the NMRPipe package (Delaglio et al., 1995) and analyzed using PIPP (Garrett et al., 1991).

The combined information obtained from the experiments CBCACONH (Grzesiek \& Bax, 1992), CBCANH (Grzesiek \& Bax, 1993), HNCA (Yamazaki et al., 1994), sensitivity-enhanced HNCO (Kay et al., 1994) and ${ }^{15} \mathrm{~N}$ separated NOESY (Bax \& Grzesiek, 1993), allowed the sequential assignment of $C^{\alpha}$ and $C^{\beta}$, as well as amide ${ }^{1} \mathrm{H}$ and ${ }^{15} \mathrm{~N}$, and ${ }^{13} \mathrm{C}$ backbone carbonyl $\left(\mathrm{C}^{\prime}\right)$ resonances. HBHACONH (Bax \& Grzesiek, 1993) was used to obtain some of the $\mathrm{H}^{\alpha}$ and $\mathrm{H}^{\beta}$ resonances. The remaining sidechain assignments were obtained using HCCH-TOCSY (Bax et al., 1990).

Dipolar couplings ${ }^{1} \mathrm{D}_{\mathrm{NH}},{ }^{1} \mathrm{D}_{\mathrm{C} \alpha \mathrm{H}},{ }^{1} \mathrm{D}_{\mathrm{C} \alpha \mathrm{C}},{ }^{1} \mathrm{D}_{\mathrm{NC}^{\prime}}$ were calculated from the difference in the corresponding $J$ splitting measured in protein samples containing liquid crystals formed by $\mathrm{fd}$ bacteriophages and in protein samples in the absence of liquid crystals. The fd bacteriophage liquid crystals were prepared by the method of Hansen et al. (1998). The concentration of bacteriophages and ${ }^{13} \mathrm{C},{ }^{15} \mathrm{~N}$-labeled protein was $\sim 15 \mathrm{mg} / \mathrm{ml}$ and $0.7 \mathrm{mM}$, respectively for ${ }^{1} \mathrm{D}_{\mathrm{NH}},{ }^{1} \mathrm{D}_{\mathrm{C} \alpha \mathrm{C}^{\prime}}$ and ${ }^{1} \mathrm{D}_{\mathrm{NC}}$ dipolar couplings measurements, and $\sim 9 \mathrm{mg} / \mathrm{ml}$ (phage), $\sim 0.4 \mathrm{~m}$ (protein) for ${ }^{1} \mathrm{D}_{\mathrm{C} \alpha \mathrm{H}}$ dipolar coupling experiment. This dilution was done to reduce ${ }^{1} \mathrm{H}^{1} \mathrm{H}$ dipolar couplings that affect the shape of the peaks and increase the error with which the $J$ values are measured. Dipolar couplings of $\mathrm{NH}$ vectors were also measured under the anisotropic conditions found in bicelles at $29^{\circ} \mathrm{C}$. The bicelles were generated by a mixture of dimyristoyl phosphatidylcholine (DMPC)/dihexanoyl phosphatidylcholine (DHPC) (Avanti Polar Lipids) at a 3:1 molar ratio and present at $3 \%(\mathrm{w} / \mathrm{v})$. The ${ }^{15} \mathrm{~N}$-labeled protein concentration in the bicelle sample was $0.6 \mathrm{mM}$. Dipolar couplings of $\mathrm{NH}$ and $\mathrm{NC}^{\prime}$ vectors were obtained from the In Phase AntiPhase (IPAP) experiment (Ottiger et al., 1998a) with and without ${ }^{13} \mathrm{C}^{\prime}$ decoupling during ${ }^{15} \mathrm{~N}$ evolution, respectively. ${ }^{1} \mathrm{D}_{\mathrm{C} \alpha \mathrm{C}^{\prime}}$ dipolar couplings were obtained from HNCO experiments without $\mathrm{C}^{\alpha}$ decoupling during $C^{\prime}$ evolution. ${ }^{1} \mathrm{D}_{\mathrm{C} \alpha \mathrm{H}}$ dipolar couplings were obtained from a three-dimensional version of ${ }^{1} \mathrm{H}^{13} \mathrm{C}$ constant time HSQC with $J$ modulation in the third dimension (Ottiger et al., 1998b). The peak intensities were fitted to yield $J_{\mathrm{C}-\mathrm{H}}$ couplings. The errors in the measured dipolar couplings, ${ }^{1} \mathrm{D}_{\mathrm{NH}}$, ${ }^{1} \mathrm{D}_{\mathrm{C} \alpha \mathrm{H}},{ }^{1} \mathrm{D}_{\mathrm{C} \alpha \mathrm{C}^{\prime}}$ and ${ }^{1} \mathrm{D}_{\mathrm{NC}^{\prime}}$ are $\sim 0.8 \mathrm{~Hz}, \sim 1.1 \mathrm{~Hz}$, $\sim 2.0 \mathrm{~Hz}, \sim 1.5 \mathrm{~Hz}$, respectively, and $\sim 0.7 \mathrm{~Hz}$ for $\mathrm{NH}$ dipolar couplings in the bicelle sample.

\section{Structure calculation}

Peak intensities from NOESY experiments $\left({ }^{13} \mathrm{C}\right.$ separated 4D NOESY (Clore et al., 1991), $\tau_{\mathrm{m}}=100 \mathrm{~ms} ;{ }^{13} \mathrm{C},{ }^{15} \mathrm{~N}$ separated 4D NOESY (Kay et al., 1990), $\tau_{\mathrm{m}}=114 \mathrm{~ms} ;{ }^{13} \mathrm{C}$ separated 3D NOESY, $\tau_{\mathrm{m}}=110 \mathrm{~ms} ;{ }^{15} \mathrm{~N}$ separated $3 \mathrm{D}$ NOESY, $\tau_{\mathrm{m}}=110 \mathrm{~ms} ;{ }^{1} \mathrm{H}-{ }^{1} \mathrm{H}$ 2D NOESY, $\tau_{\mathrm{m}}=150 \mathrm{~ms}$ ) were translated into a continuous distribution of interproton distances. A summation averaging $\left[\left(\Sigma r^{-6}\right)^{-1 / 6}\right]$ was used to obtain distances from intensities of nonstereospecifically assigned methylene protons, methyl groups and $\mathrm{H}^{\delta}, \mathrm{H}^{\varepsilon}$ protons of Tyr and Phe residues. Structures were calculated using the program XPLOR (Brünger, 1993) modified to include dipolar coupling restraints (Tjandra et al., 1997; Clore et al., 1998b). A quadratic half-open square well potential was used for residues belonging to loopV-VI and loop VI-VII, and a quadratic harmonic potential was applied for dipolar couplings of the remaining residues. The alignment tensors are represented by two separate pseudo-molecules containing four atoms, whose bonds correspond to the three orthogonal alignment axis. The appropriate orientation of these pseudo-molecules with respect to the molecular frame is calculated through a minimization 
procedure of the differences between the observed and the calculated dipolar couplings. The calculated dipolar couplings in the bacteriophage and bicelle media were derived from their separate tensorial $\mathrm{Da}$ and $R$ values. Therefore, the fitting was done using two different coordinate systems, one for each set of dipolar couplings. The angles between the two tensor axis are: $X_{\text {bicelle }}-X_{\text {phage }}=57.35^{\circ}, Y_{\text {bicelle }}-Y_{\text {phage }}=56.74^{\circ}$, $Z_{\text {bicelle }}-Z_{\text {phage }}=9.76^{\circ}$.

The starting structure was heated to $3000 \mathrm{~K}$ and cooled in 20,000 steps for $0.002 \mathrm{ps}$ in the simulated annealing process. The final values of the force constants used in the simulated annealing calculations are as follows; $1000 \mathrm{kcal}^{\mathrm{mol}^{-1}} \AA^{-2}$ for bond lengths, $500 \mathrm{kcal} \mathrm{mol}^{-1} \mathrm{rad}^{-2}$ for angles and improper torsions, $4 \mathrm{kcal} \mathrm{mol}^{-1} \AA^{-4}$ for the quadratic van der Waals repulsion term, $30 \mathrm{kcal} \mathrm{mol}^{-1} \AA^{-2}$ for NOE-derived distance restraints, $50 \mathrm{kcal} \mathrm{mol}^{-1} \AA^{-2}$ for generic hydrogen bond restraints, $10 \mathrm{kcal} \mathrm{mol}^{-1} \mathrm{rad}^{-2}$ for TALOS $\phi$ and $\psi$ restraints, $0.48 \mathrm{kcal} \mathrm{mol}^{-1} \mathrm{~Hz}^{-2}, 0.48 \mathrm{kcal} \mathrm{mol}^{-1} \mathrm{~Hz}^{-2}$ $0.72 \mathrm{kcal} \mathrm{mol}^{-1} \mathrm{~Hz}^{-2}, 0.12 \mathrm{kcal} \mathrm{mol}^{-1} \mathrm{~Hz}^{-2}$, for $\mathrm{NH}$, $\mathrm{C}^{\alpha} \mathrm{H}, \mathrm{NC}^{\prime}$ and $\mathrm{C} \alpha \mathrm{C}^{\prime}$ dipolar couplings of the bacteriophage sample, respectively, and $0.72 \mathrm{kcal} \mathrm{mol}^{-1} \mathrm{~Hz}^{-2}$ for $\mathrm{NH}$ dipolar coupling in the bicelle sample. With these force constants the calculated structures satisfy the experimental dipolar couplings with r.m.s.d. values close to the estimated experimental errors derived from the reproducibility of the data. Two restraints were used per hydrogen bond (e.g. $r_{\mathrm{NH}-\mathrm{O}}=1.5-2.5 \AA$ and $\left.r_{\mathrm{N}-\mathrm{O}}=2.4-3.6 \AA\right)$.

\section{Protein Data Bank accession code}

The coordinates of the ensemble of 20 structures, the list of experimental NMR restraints, together with ${ }^{1} \mathrm{H}$, ${ }^{15} \mathrm{~N}$ and ${ }^{13} \mathrm{C}$ chemical shifts assignments have been deposited in the Brookhaven Protein Data Bank with accession codes $1 \mathrm{cmz}$ and $\mathrm{r} 1 \mathrm{cmzmr}$.

\section{Acknowledgments}

We are grateful to Dr Hank Fales for analyzing the mass spectra of the protein. We thank Dr Daniel Libutti and Dr Solly Weiler for plasmid sequencing and help with plasmid purification, respectively, and Dr John Louis for providing us with a bacteriophage sample. We are thankful to Dr Frank Delaglio and Dr Dan Garrett for software support and help with NMRPipe/TALOS and PIPP programs, respectively.

E. de A. is recipient of a postdoctoral fellowship from the Human Frontier Science Program.

\section{References}

Archer, S. J., Ikura, M., Torchia, D. A. \& Bax, A. (1991). An alternative 3D NMR technique for correlating backbone ${ }^{15} \mathrm{~N}$ with side-chain $\mathrm{H}_{\beta}$ resonances in larger proteins. J. Magn. Reson. 95, 636-641.

Bax, A. \& Grzesiek, S. (1993). Methodological advances in protein NMR. Acc. Chem. Res. 26, 131-138.

Bax, A. \& Tjandra, N. (1997). High-resolution heteronuclear NMR of human ubiquitin in an aqueous liquid crystalline medium. J. Biomol. NMR. 10, 289-292.

Bax, A., Clore, G. M. \& Gronenborn, A. M. (1990). ${ }^{1} \mathrm{H}-{ }^{1} \mathrm{H}$ correlation via isotropic mixing of ${ }^{13} \mathrm{C}$ magnetization, a new three-dimensional approach for assigning ${ }^{1} \mathrm{H}$ and ${ }^{13} \mathrm{C}$ spectra of ${ }^{13} \mathrm{C}$-enriched proteins. J. Magn. Reson. 88, 425-431.

Berman, D. M. \& Gilman, A. G. (1998). Mammalian RGS proteins: Barbarians at the gate. J. Biol. Chem. 273, 1269-1272.

Berman, D. M., Wilkie, T. M. \& Gilman, A. G. (1996a). GAIP and RGS4 are GTPase-activating proteins for the $G_{i}$ subfamily of $G$ protein $\alpha$ subunits. Cell, 86, 445-452.

Berman, D. M., Kozasa, T. \& Gilman, A. G. (1996b). The GTPase activating protein RGS4 stabilizes the transition state for nucleotide hydrolysis. J. Biol. Chem. 271, 27209-27212.

Brünger, A. T. (1993). XPLOR Manual Version 3. 1, Yale University, New Haven, CT.

Chen, C. \& Lin, S. C. (1998). The core domain of RGS16 retains G-protein binding and GAP activity in vitro, but is not functional in vivo. FEBS Letters, 422, 359362.

Clore, G. M., Kay, L. E., Bax, A. \& Gronenborn, A. M. (1991). Four-dimensional ${ }^{13} \mathrm{C} /{ }^{13} \mathrm{C}$-edited nuclear Overhauser enhancement spectroscopy of a protein in solution: application to interleukin $1 \beta$. Biochemistry, 30, 12-18.

Clore, M. G., Starich, M. R. \& Gronenborn, A. M. (1998a). Measurement of residual dipolar couplings of macromolecules aligned in the nematic phase of a colloidal suspension of rod-shaped viruses. J. Am. Chem. Soc. 120, 10571-10572.

Clore, M. G., Gronenborn, A. M. \& Bax, A. (1998b). A robust method for determining the magnitude of the fully asymmetric alignment tensor of oriented macromolecules in the absence of structural information. J. Magn. Reson. 133, 216-221.

Clore, M. G., Gronenborn, A. M. \& Tjandra, N. (1998c). Direct structure refinement against residual dipolar couplings in the presence of rhombicity of unknown magnitude. J. Magn. Reson. 131, 159-162.

Coleman, D. E., Berghuis, A. M., Lee, E., Linder, M. E., Gilman, A. G. \& Sprang, S. (1994). Structures of the active conformations of $\mathrm{G} \alpha_{\mathrm{i} 1}$ and the mechanism of GTP hydrolysis. Science, 265, 1405-1412.

Cornilescu, G., Delaglio, F. \& Bax, A. (1999). Protein backbone angle restraints from searching a database for chemical shift and sequence homology. J. Biomol. NMR. 13, 289-302.

Delaglio, F., Grzesiek, S., Vuister, G. W., Zhu, G., Pfeifer, J. \& Bax, A. (1995). NMRPipe: a multidimensional spectral processing system based on UNIX Pipes. J. Biomol. NMR, 6, 277-293.

De Vries, L. \& Farquhar, M. G. (1999). RGS proteins: more than just GAPs for heterotrimeric $G$ proteins. Trends Cell Biol. 9, 138-144.

De Vries, L., Mousli, M., Wurmser, A. \& Farquhar, M. G. (1995). GAIP, a protein that specifically interacts with the trimeric $G$ protein $G \alpha_{i 3}$, is a member of a protein family with a highly conserved core domain. Proc. Natl Acad. Sci. USA, 92, 11916-11920.

De Vries, L., Elenko, E., Hubler, L., Jones, T. L. Z. \& Farquhar, M. G. (1996). GAIP is a membraneanchored by palmitoylation and interacts with the activated (GTP-bound) form of $\mathrm{G} \alpha_{\mathrm{i}}$ subunits. Proc. Natl Acad. Sci. USA, 93, 15203-15208.

De Vries, L., Elenko, E., McCaffery, J. M., Fischer, T., Hubler, L., McQuistan, T., Watson, N. \& Farquhar, M. G. (1998a). RGS-GAIP, a GTPase-activating protein for $\mathrm{G} \alpha_{\mathrm{i}}$ heterotrimeric $\mathrm{G}$ proteins, is located on clathrin-coated vesicles. Mol. Biol. Cell. 9, 1123-1134. 
De Vries, L., Lou, X., Zhao, G., Zheng, B. \& Farquhar, M. G. (1998b). GIPC, a PDZ domain containing protein, interacts specifically with the $C$ terminus of RGS-GAIP. Proc. Natl Acad. Sci. USA, 95, 1234012345.

Drohat, A. C., Bax, A., Tjandra, N., Baldisseri, D. \& Weber, D. J. (1999). The use of dipolar couplings for determining the solution structure of Rat ApoS100B. Protein Sci. 8, 800-809.

Druey, K. M., Blumer, K. J., Kang, V. H. \& Kehrl, J. H. (1996). Inhibition of G-protein-mediated MAP kinase activation by a new mammalian gene family. Nature, 379, 742-746.

Faurobert, E. \& Hurley, J. B. (1997). The core domain of a new retina specific RGS protein stimulates the GTPase activity of transducin in vitro. Proc. Natl Acad. Sci. USA, 94, 2945-2950.

Fischer, T., Elenko, E., McCaffery, J. M., De Vries, L. \& Farquhar, M. G. (1999). Clathrin-coated vesicles bearing $\mathrm{G} \alpha$-interacting protein possess GTPase-activating protein activity in vitro. Proc. Natl Acad. Sci. $U S A$, in the press.

Freissmuth, M., Casey, P. J. \& Gilman, A. G. (1989). G proteins control diverse pathways of transmembrane signaling. FASEB J. 3, 2125-2131.

Garrett, D. S., Powers, R., Gronenborn, A. M. \& Clore, G. M. (1991). A common sense approach to peak picking in two-, three- and four dimensional spectra using automatic computer analysis of contour diagrams. J. Magn. Reson. 95, 214-220.

Grzesiek, S. \& Bax, A. (1992). Correlating backbone amide and side-chain resonances in larger proteins by multiple relayed triple resonance NMR. J. Am. Chem. Soc. 114, 6291-6293.

Grzesiek, S. \& Bax, A. (1993). Amino acid type determination in the sequential assignment of uniformly ${ }^{13} \mathrm{C} /{ }^{15} \mathrm{~N}$-enriched proteins. J. Biomol. NMR, 3, 185204.

Hansen, M. R., Mueller, L. \& Pardi, A. (1998). Tunable alignment of macromolecules by filamentous phage yields dipolar coupling interactions. Nature Struct. Biol. 5, 1065-1074.

Hart, M. J., Jiang, X., Kozasa, T., Roscoe, W., Singer, W. D., Gilman, A. G., Sternweis, P. C. \& Bollag, G. (1998). Direct stimulation of the guanine nucleotide exchange activity of P115 RhoGEF by $\mathrm{G} \alpha_{12}$. Science, 280, 2112-2114.

Hepler, J. R. \& Gilman, A. G. (1992). G proteins. Trends Biochem. Sci. 17, 383-387.

Hepler, J. R., Berman, D. M., Gilman, A. G. \& Kozasa, T. (1997). RGS4 and GAIP are GTPase-activating proteins for $\mathrm{G}_{\mathrm{q}} \alpha$ and block activation of phospholipase $C^{\beta}$ by $\gamma$-thio-GTP-G ${ }_{\mathrm{q}} \alpha$. Proc. Natl Acad. Sci. USA, 94, 428-432.

Holm, L. \& Sander, C. (1993). Protein structure comparison by alignment of distance matrices. J. Mol. Biol. 233, 123-138.

Kay, L. E., Clore, G. M., Bax., A. \& Gronenborn, A. M. (1990). Four-dimensional heteronuclear triple-resonance NMR spectroscopy of interleukin-1 $\beta$ in solution. Science, 249, 411-414.

Kay, L. E., Xu, G. Y. \& Yamazaki, T. (1994). Enhancedsensitivity triple-resonance spectroscopy with minimal $\mathrm{H}_{2} \mathrm{O}$ saturation. J. Magn. Reson. 109, 129-133.

Kaziro, Y., Itoh, H., Kozasa, T., Nakafuku, M. \& Satoh, T. (1991). Structure and function of signal-transducing GTP-binding proteins. Annu. Rev. Biochem. 60, 349-400.
Koelle, M. R. \& Horvitz, H. R. (1996). EGL-10 regulates $G$ protein signaling in the $C$. elegans nervous system and shares a conserved domain with many mammalian proteins. Cell, 84, 115-125.

Koradi, R., Billeter, M. \& Wüthrich, K. (1996). MOLMOL: a program for display and analysis of macromolecular structures. J. Mol. Graph. 14, 51-55.

Kozasa, T., Jiang, X., Hart, M. J., Sternweis, P. M., Singer, W. D., Gilman, A. G., Bollag, G. \& Sternweis, P. C. (1998). P115 RhoGEF, a GTPase activating protein for $\mathrm{G} \alpha_{12}$ and $\mathrm{G} \alpha_{13}$. Science, 280, 2109-2111.

Laskowski, R. A., Rullman, J. A. C., MacArthur, M. W., Kaptein, R. \& Thornton, J. M. (1996). AQUA and PROCHECK-NMR: programs for checking the quality of protein structures solved by NMR. J. Biomol. NMR, 8, 477-486.

Natochin, M., McEntaffer, R. L. \& Artemyev, N. O. (1998). Mutational analysis of the Ans residue essential for RGS protein binding to G-proteins. J. Biol. Chem. 273, 6731-6735.

Neer, E. J. (1995). Heterotrimeric G proteins: organizers of transmembrane signals. Cell, 80, 249-257.

Ottiger, M. \& Bax, A. (1999). Bicelle-based liquid crystals for NMR-measurement of dipolar couplings at acidic and basic pH values. J. Biomol. NMR, 13, 187191.

Ottiger, M., Delaglio, F. \& Bax, A. (1998a). Measurement of $J$ and dipolar couplings from simplified twodimensional NMR spectra. J. Magn. Reson. 131, 373378.

Ottiger, M., Delaglio, F., Marquardt, J. L., Tjandra, N. \& Bax, A. (1998b). Measurement of dipolar couplings for methylene and methyl sites in weakly oriented macromolecules and their use in structure determination. J. Magn. Reson. 134, 365-369.

Popov, S., Yu, K., Kozasa, T. \& Wilkie, T. (1997). The regulators of $G$ protein signaling (RGS) domains of RGS4, RGS10, and GAIP retain GTPase activating protein activity in vitro. Proc. Natl Acad. Sci. USA, 94, 7216-7220.

Spera, S. \& Bax, A. (1991). Empirical correlation between protein backbone conformation and $\mathrm{C}^{\alpha}$ and $\mathrm{C}^{\beta}{ }^{13} \mathrm{C}$ nuclear magnetic resonance chemical shifts. J. Am. Chem. Soc. 113, 5490-5492.

Tesmer, J. J. G., Berman, D. M., Gilman, A. G. \& Sprang, S. R. (1997). Structure of RGS4 bound to $\mathrm{AlF}_{4}^{-}$-activated $\mathrm{G} \alpha_{\mathrm{i} 1}$ : stabilization of the transition state for GTP hydrolysis. Cell, 89, 251-261.

Tjandra, N. \& Bax, A. (1997). Direct measurement of distances and angles in biomolecules by NMR in a dilute liquid crystalline medium. Science, 278, 11111114.

Tjandra, N., Omichinski, J. G., Gronenborn, A., Clore, M. G. \& Bax, A. (1997). Use of dipolar ${ }^{1} \mathrm{H}^{-15} \mathrm{~N}$ and ${ }^{1} \mathrm{H}-{ }^{13} \mathrm{C}$ coupling in the structure determination of magnetically oriented macromolecules in solution. Nature Struct. Biol. 4, 732-738.

Vuister, G. W., Kim, S.-J., Wu, C. \& Bax, A. (1994). 2D and $3 \mathrm{D}$ NMR study of phenylalanine residues in proteins by reverse isotopic labeling. J. Am. Chem. Soc. 116, 9206-9210.

Wang, J., Ducret, A., Tu, Y., Kozasa, T., Aebersold, R. \& Ross, E. M. (1998). RGSZ1, a $\mathrm{G}_{\mathrm{z}}$-selective RGS protein in brain. Structure, membrane association, regulation by $\mathrm{G} \alpha_{\mathrm{z}}$ phosphorilation, and relationship to a Gz GTPase-activating protein subfamily. J. Biol. Chem. 273, 26014-26025. 
Wüthrich, K. (1986). NMR of Proteins and Nucleic Acids, John Wiley \& Sons, Inc., New York.

Xu, X., Zeng, W., Popov, S., Berman, D. M., Davignon, I., Yu, K., Yowe, D., Offermanns, S., Muallem, S. \& Wilkie, T. M. (1999). RGS proteins determine the signaling specificity of $\mathrm{G}_{\mathrm{q}}$-coupled receptors. J. Biol. Chem. 274, 3549-3556.
Yamazaki, T., Lee, W., Revington, M., Mattiello, D. L., Dahlquist, F. W., Arrowsmith, C. H. \& Kay, L. E. (1994). An HNCA pulse scheme for the backbone assignment of ${ }^{15} \mathrm{~N},{ }^{13} \mathrm{C},{ }^{2} \mathrm{H}$-labeled proteins: application to a $37-\mathrm{kDa}$ Trp Represor-DNA complex. J. Am. Chem. Soc. 116, 6464-6465.

Edited by P. E. Wright

(Received 21 May 1999; received in revised form 1 July 1999; accepted 1 July 1999) 